\title{
Adenylate Gyclase Activity in Immature Rabbit Lung
}

\author{
Gynthia T. Barretr, ${ }^{[18]}$ Alex Sevanian, and Solomon A. Kaplan \\ Department of Pediatrics, University of California at Los Angeles School of Medicine, Los Angeles, California, USA
}

\begin{abstract}
Extract
Adenylate cyclase activity of lung homogenates from fetal and neonatal rabbits is considerably higher than that found in adult animals. This activity does not change significantly between 21 and 31 days postconception, but maturational changes are observed in responses of adenylate cyclase activity to incubation with epinephrine, glucagon, and $\mathrm{NaF}$. Epinephrine stimulated adenylate cyclase activity at all ages studied, $21,24,27,30$ and 31 days postconception. NaF depressed adenylate cyclase activity at 21 and 24 days but thereafter stimulated it at 27, 30, and 31 days. Glucagon stimulated adenylate cyclase activity only after delivery. We conclude that hormonally mediated responses in formation of adenosine $3^{\prime}, 5^{\prime}$-monophosphate (cyclic AMP) occur in the lung of the fetal animal.
\end{abstract}

\section{Speculation}

Adenylate cyclase may be important in regulating pulmonary phospholipid biosynthesis in fetal animals. Activity of adenylate cyclase can be augmented by epinephrine in fetal lung homogenates and may mediate growth of the lung or premature formation of pulmonary surface active phospholipids.

\section{Introduction}

Since the identification of cyclic AMP, this compound has been recognized to occupy a major regulatory role in tissue metabolism [8]. Many hormones appear to exert effects through alteration of intracellular concentrations of cyclic AMP in their target tissues. It is thought that these hormones act through specific receptors which are functionally coupled with an adenylate cyclase system either to increase or decrease intracellular concentrations of cyclic AMP. Cyclic AMP has been shown to be present in many organs, including the lung. Several authors have reported adenylate cyclase activity in mammalian lungs and its stimulation by various agents [12-14], but adenylate cyclase activity has not been studied in fetal lung previously.

In liver, adenylate cyclase is important in metabolism of glycogen, mediated by glucagon and epinephrine [11]. Glycogen is also abundant in fetal lungs. Sorokin has postulated that glycogen is important for purposes of lung growth [10]; in addition, glycogen is probably a major precursor of surfactant $[1,3]$. After making the preliminary observation that adenylate cyclase activity in fetal lung homogenates is high, we conducted a series of experiments to determine the effects of fetal maturation on adenylate cyclase activity and its response to agents which may exert a physiologic role in fetal lung development and its response to stressful stimuli.

\section{Materials and Methods}

We studied 20 litters of New Zealand albino rabbits with dated pregnancies, four each at 21,24, 27, 30, and 31 days of gestation. The 31-day animals were newly born and delivered naturally. Does were killed with intravenous administration of Nembutal in anesthetic doses followed by intravenous $\mathrm{KCl}$ [8].

Several fetuses from each litter were removed and 
their lungs excised intact into $0.05 \mathrm{~m}$ Tris- $\mathrm{HCl}, \mathrm{pH}$ 7.6. Blood vessels and major airways were dissected off as much as possible. The tissue was homogenized in a motor-driven, Teflon-glass homogenizer, $100 \mathrm{mg}$ lung tissue $/ \mathrm{ml}$ of Tris-HCl buffer. All procedures were carried out at $0-4^{\circ}$ unless otherwise specified. The homogenate was analyzed for adenylate cyclase activity by the method of Krishna et al. [4], with minor modifications as suggested by Pohl et al. [7], as follows. Theophylline was added in concentrations of $10 \mathrm{~mm}$ because, in its absence, cyclic AMP production was diminished. The volume of the assay solution was 50 $\mu 1$. Additions of glucagon were $800 \mu \mathrm{g}$ /assay tube, of $\mathrm{NaF} 63 \mu \mathrm{g}$, and of epinephrine $0.5 \mu \mathrm{g}$. Corrections were made for cyclic AMP lost during its separation from other ${ }^{32} \mathrm{P}$-containing compounds, and adenylate cyclase activity was expressed as picomoles of ATP converted to cyclic AMP per milligram of tissue protein. Protein was measured by the method of Lowry et al. [5]. Statistical analysis included paired analysis by the Student $t$ test, analysis of variance, and Duncan's New Multiple Range Test.

\section{Results}

Mean values \pm 1 sD of adenylate cyclase activity for each age are shown in Table 1 . Control values for adenylate cyclase activity did not vary significantly during the period studied.

Maximal stimulation of adenylate cyclase activity at each age occurred with epinephrine, although at 27 and 30 days, stimulation by $\mathrm{NaF}$ was of equal magnitude to that by epinephrine.

Changes in adenylate cyclase activity produced by the various agents are shown better as percentage changes from the control values (Fig. 1). Here it becomes apparent that only epinephrine stimulates adenylate

Table $I$. Mean adenylate cyclase activity ( $\pm 1 \mathrm{sD})$

\begin{tabular}{|c|c|c|c|c|}
\hline \multirow{2}{*}{ Age, days } & \multicolumn{4}{|c|}{ Activity, pmol ATP converted to cyclic AMP/mg protein/10 min } \\
\hline & Control & Glucagon & $\mathrm{NaF}$ & Epinephrine \\
\hline \multirow[t]{2}{*}{21} & 438.5 & 423.0 & 362.8 & 498.2 \\
\hline & \pm 97.8 & \pm 89.3 & \pm 81.1 & \pm 100.2 \\
\hline \multirow[t]{2}{*}{24} & 471.8 & 449.8 & 405.0 & 614.8 \\
\hline & \pm 90.5 & \pm 96.1 & \pm 59.9 & \pm 106.1 \\
\hline \multirow[t]{2}{*}{27} & 457.0 & 482.8 & 608.5 & 610.5 \\
\hline & \pm 30.2 & \pm 82.7 & \pm 186.9 & \pm 56.9 \\
\hline \multirow[t]{2}{*}{30} & 431.5 & 462.0 & 645.5 & 649.2 \\
\hline & \pm 97.5 & \pm 129.5 & \pm 252.1 & \pm 211.8 \\
\hline \multirow[t]{2}{*}{31} & 390.2 & 429.2 & 503.2 & 712.8 \\
\hline & \pm 73.7 & \pm 84.8 & \pm 67.9 & \pm 143.4 \\
\hline
\end{tabular}

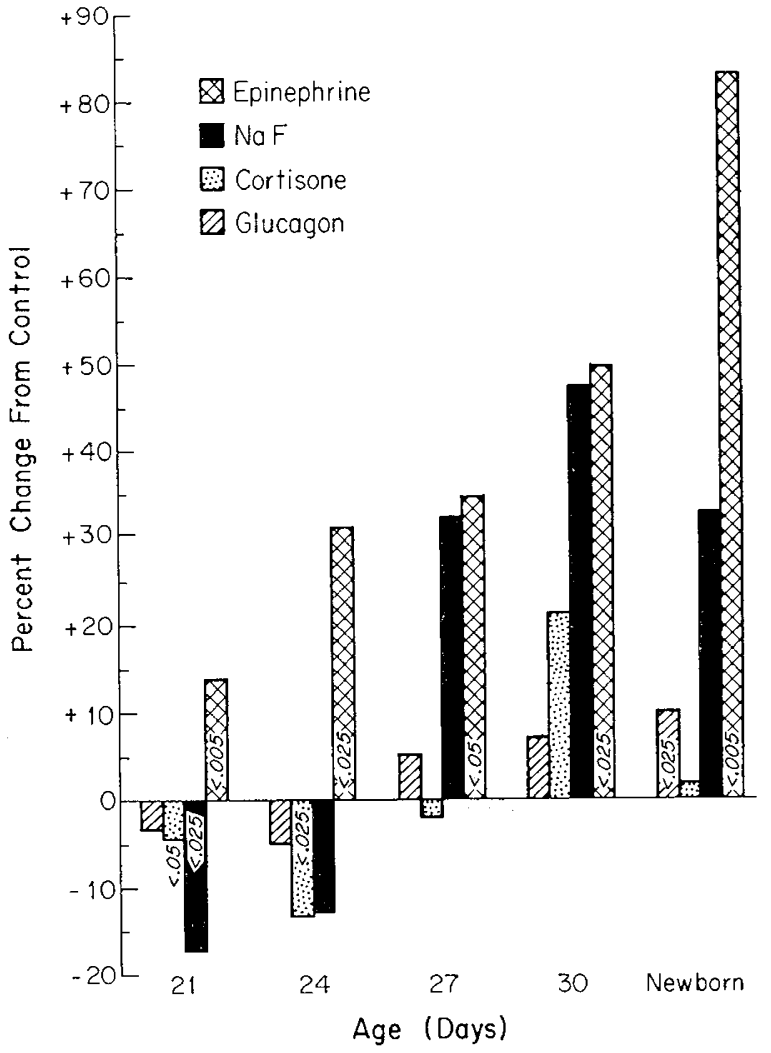

Fig. 1. Mean changes of adenylate cyclase activity of lung homogenates expressed as percentage of changes from control values for tissues incubated with epinephrine, glucagon, and NaF. Significant changes using paired $t$ test are shown in appropriate bars. Four litters comprise each age group.

cyclase activity in the most immature fetuses at 21 and 24 days. Glucagon and NaF depress adenylate cyclase activity at these ages although this depression is significant only with $\mathrm{NaF}$ at 21 days. During further maturation, changes in the response of lung homogenate adenylate cyclase activity to the various agents occurred. Epinephrine continued to stimulate adenylate cyclase activity significantly at all ages (paired $t$ test). Mean stimulation was $34.5 \%, 49.8 \%$, and $82.8 \%$ at 27,30 , and 31 days after conception.

In general, responses to other agents showed considerable variation, and mean changes in adenylate cyclase activity were not significant using paired analysis. Using Duncan's New Multiple Range Test, however, the following changes were noted. NaF stimulated adenylate cyclase activity significantly $(P<$ 0.05 ) at 27,30 , and 31 days postconception with mean increases of $32.5 \%, 47.8 \%$, and $32.5 \%$, respectively. At 27 and 30 days, these responses were almost identical with those produced by epinephrine. Glucagon also 
stimulated adenylate activity at all three ages with mean increases of $5.8 \%, 7.3 \%$, and $10.0 \%$ at 27,30 , and 31 days. Only the response at 31 days was significant $(P<0.05)$. When the percentage of change in responses was averaged for each age using analysis of variance, we determined that the responses were significantly different at every age $(P<0.001)$ and increased progressively with increasing age.

\section{Discussion}

Several maturational aspects of adenylate cyclase activity are of interest.

\section{Action of $\mathrm{NaF}$}

In the least mature rabbit fetuses, at 21 and 24 days, $\mathrm{NaF}$ clearly had an inhibitory effect upon adenylate cyclase activity. This inhibitory effect has not been reported previously, although it has been postulated. Schmidt and his co-workers [9], using very large concentrations of this agent, reported only minimal stimulation of adenylate cyclase activity by $\mathrm{NaF}$ in neonatal rat brain before 9 days of age. At 9 days of age, there was significant stimulation of adenylate cyclase activity by $\mathrm{NaF}$ which persisted in older animals. Robison et al. [8] have suggested that stimulation of adenylate cyclase activity by fluoride ion may be a maturational phenomenon and a reversal of inhibitory effect present previously.

\section{Action of Hormones}

We also observed a maturational phenomenon in the responses of fetal lung adenylate cyclase activity to epinephrine and glucagon.

In all fetal age groups, the effects of glucagon paralleled those of fluoride, although in general, glucagon effects, both inhibitory and stimulatory, were less than those of fluoride and were only significant after delivery.

Glucagon is well known to mediate glycogenolysis and formation of glucose through the adenylate cyclase system [6]. This hormone has best been studied in liver, and Kaplan and Lippe [2] have recently reported adenylate cyclase activity responses to glucagon in fetal and neonatal rat liver plasma membranes.

Like the liver, the fetal lung is rich in glycogen, a primary substrate for glucose formation. It is not surprising, therefore, that glucagon stimulates adenylate cyclase activity similarly in the two organs, although the only significant response of adenylate cy- clase activity to glucagon in fetal lungs occurred in newborn animals.

In contrast to the other hormones, epinephrine stimulated adenylate cyclase activity at all fetal ages and in the newly born rabbit lung homogenates. This response increased at each age with increasing maturity and was significant at all ages.

In addition to maturation of adenylate cyclase responses to differing specific stimuli which we observed, we also observed a total increase in stimulation with advancing gestational age, a nonspecific maturational phenomenon.

\section{Summary}

Adenylate cyclase activity in fetal lung homogenates is greater than has been reported in other organs. Maturational changes in responses of adenylate cyclase to various hormones and fluoride ions occur during the last 10 days of fetal life. Our observations support the hypothesis that epinephrine stimulation of adenylate cyclase activity occurs earlier in development and to a greater degree though a separate receptor system than does stimulation by glucagon.

\section{References and Notes}

1. Buckingham, S., Heineman, H. O., Somers, S. C., AND MaNary, W. F.: Phospholipid synthesis in the large pulmonary alveolar cell. Amer. J. Pathol., 48: 1027 (1966).

2. Kaplan, S. A., And Lippe, B. M.: Adenylate cyclase (AC) response to glucagon of fetal liver plasma membranes. Pediat. Res., 7: 325 (1973).

3. KiKkawa, Y., Kaibara, M., Motoyama, E. K., OrZalesi, M. M., AND Cook, C. D.: Morphologic development of fetal rabbit lung and its acceleration with cortisol. Amer. J. Pathol., 64: 423 (1971).

4. Krishna, G., Weiss, B., And Brodie, B. B.: A simple, sensitive method for the assay of adenylate cyclase. J. Pharmacol. Exp. Ther., 163: 379 (1968).

5. Lowry, O. H., Rosebrough, N. J., Farr, A. L., and Randall, R. J.: Protein measurement with the Folin phenol reagent. J. Biol. Chem., 193: 265 (1951).

6. Makman, M. H., and Sutherland, E. W.: Use of liver adenyl cyclase for assay of glucagon in human gastrointestinal tract and pancreas. Endocrinology, 75: 217 (1964).

7. Pohl, S. L., Birnbaumer, L., And Rodbell, M.: The glucagon sensitive adenylate cyclase system in plasma membranes of rat liver. J. Biol. Chem., 246: 1849 (197I).

8. Robison, G. A., Butcher, R. W., and Sutherland, E. W.: Cyclic AMP, p. 82 (Academic Press, New York, 1971).

9. Schimdt, M. J. Palmer, E. C., Detrbam, W. D., and Robison, G. A.: Cyclic AMP and adenyl cyclase in the developing rat brain. Develop. Psychobiol., 3: 53 (1970).

10. Sorokin, S.: A study of development in organ cultures of mammalian Iungs. Develop. Biol., 3: 60 (1961).

11. Sutherland, E. W., and Rall, T. W.: The relation of 
adenosine $3^{\prime}, 5^{\prime}$-monophosphate and phosphorylase to the actions of catecholamines and other hormones. Pharmacol. Rev., 12: 265 (1960).

12. Weinryb, I., Chasin, M., Free, C. A., Harris, D. N., Goldenberg, H., Mrchel, I. M., Paik, V. S., Phillips, M., Samaniego, S., AND Hess, S. M.: Effects of therapeutic agents on cyclic AMP metabolism in vitro. J. Pharmaceut. Sci., 155: 1567 (1972).

13. Weinryb, I., Michel, I. M., Alicino, J. F., And Hess, S. M.: Effects of barbiturate derivatives, sulfhydryl reagents, and oxidizing agents on the activity of adenylate cyclase from guinea pig heart and lung. Arch. Biochem. Biophys., 146: 591 (1971).

14. WeInryb, I., Michel, I. M., AND Hess, S. M.: Adenylate cyclase from guinea pig lung: Further characterization and inhibitory effects of substrate analogs and cyclic nucleotides. Arch. Biochem. Biophys., 154: 240 (1973).

15. Presented in part before the Society for Pediatric Research, May, 1973, San Francisco, California.

16. Computing assistance was obtained from the Health Sciences Computing Facility, UCLA, sponsored by National Institutes of Health Resources Grant no. RR-3.

17. This research has been supported in part by United States Public Health Service Grant nos. HD 05443 and HD 06779 and an institutional GRSG.

18. Requests for reprints should be addressed to: C. T. BARRETT, M.D., Division of Neonatology, UCLA School of Medicine, Center for the Health Sciences, Los Angeles, Calif. 90024 (USA).

19. Accepted for publication November 21, 1973. 